\title{
El nuevo marco jurídico para la reconversión y la dinamización del sector de la construcción y la vivienda
}

\author{
Manuel Moreno Linde
}

Doctor en Derecho. Profesor Colaborador de Derecho Administrativo.

Universidad de Málaga

\begin{abstract}
SUMARIO: I. LAS DIFICULTADES DEL SEGTOR DE LA CONSTRUCGIÓN Y LA VIVIENDA. LA NECESIDAD DE SU REGONVERSIÓN. II. LAS NUEVAS DIREGTRICES DE LAS POLÍTICAS SOBRE GONSTRUCGIÓN Y VIVIENDA. 1. Hacia un desarrollo sostenible. La ciudad compacta. 2. Regeneración y renovación del tejido urbano y rehabilitación edificatoria. 3. Medidas específicas en materia de vivienda: rehabilitación y fomento de alquiler. A. Rehabilitación de viviendas. B. Fomento del alquiler. C. Otras medidas para la protección del derecho a la vivienda. 4. La regularización de las actuaciones urbanísticas ilegales. III. RECAPITULACIÓN. IV. REFERENCIAS.
\end{abstract}

\begin{abstract}
RESUMEN: La situación de extrema dificultad en la que se encuentra el sector de la construcción y la vivienda ha motivado una profunda reflexión sobre un modelo productivo que adolece de problemas estructurales, particularmente su carácter eminentemente expansivo y su apoyo excesivo en la creación de vivienda nueva. En ese contexto, se propone una reconversión de esta rama de actividad que se oriente hacia la ciudad ya existente - en lugar de hacia nuevos crecimientos - mediante la regeneración del tejido urbano, la rehabilitación edificatoria y la dinamización del mercado del alquiler de vivienda. Adicionalmente, los poderes públicos deben abordar en sus políticas un problema cada vez más extendido: la consolidación de actuaciones urbanísticas ejecutadas al margen de la legalidad urbanística.
\end{abstract}

PALABRAS CLAVE: Construcción, Vivienda, Desarrollo Urbano Sostenible, Regularización Urbanística.

ABSTRACT: Nowadays, the building and housing sector is in such an extremely difficult situation that has prompted a deep consideration about a productive model which shows clear structural problems. Particularly notable of this model are the expanding characteristics and the excessive support on new housing construc- 
tion. In this context, a restructuring of this particular field of the economic activity is proposed in order to be directed towards the existing city, instead of a growing city, by regenerating the urban structure, restoring buildings and stimulating house renting. In addition, authorities should deal in their political plans with an increasingly rife problem: the strengthening of urban actions implemented on the fringes of the urban law.

KEY WORDS: Construction, Housing, Sustainable Urban Development, Urban Regularization.

\section{LAS DIFICULTADES DEL SEGTOR DE LA GONSTRUG- CIÓN Y LA VIVIENDA. LA NECESIDAD DE SU RECON- VERSIÓN}

Es un dato de sobra conocido que la situación del sector de la construcción y la vivienda en España, en un contexto de crisis económica general, es de extrema dificultad. Así lo corroboran los distintos indicadores expresivos del estado de salud de esta rama de actividad, que tradicionalmente ha tenido un peso muy importante en el conjunto de los sectores productivos de nuestro País ${ }^{1}$.

Así, en primer lugar, es reseñable la caída de la inversión en obra pública experimentada desde el año 2010, que se refleja en el descenso del volumen de la licitación pública en construcción. Debe señalarse, no obstante, que en el año 2013 y primer semestre de 2014 se ha producido un incremento en dicha inversión, cuyo valor, no obstante, está muy alejado del correspondiente a los años inmediatamente anteriores al inicio de la crisis económica en la que se halla aún inmersa España ${ }^{2}$.

Una segunda circunstancia a considerar es la importante disminución que se ha producido en el otorgamiento de licencias de obra nueva y de certificados fin obra desde el inicio de la crisis - en torno a 2007 - lo que viene a significar que hay muchos menos edificios que inician su construcción y que se concluyen. La evolución ha

${ }^{1}$ La participación porcentual de esta rama de actividad en el PIB español se ha situado desde el inicio del presente siglo entre el 10 y el $12 \%$ aproximadamente. No obstante, el sector ha comenzado a perder importancia los últimos años, de suerte que en 2012 su peso en el conjunto de la actividad productiva representó ya el 7,9 \% del PIB. Vid. página web del Instituto Nacional de Estadística. Cuentas económicas. Contabilidad nacional de España. PIB a precios de mercado. http://www.ine.es/.

${ }^{2}$ Esta conclusión se extrae de la información estadística que facilita la página web del Ministerio de Fomento sobre construcción (licitación oficial en construcción) http://www.fomento.gob.es/. 
sido en diferente en el caso de las intervenciones de rehabilitación, que han experimentado, en general, un aumento en los últimos años ${ }^{3}$.

Una referencia aparte merece el mercado de la vivienda, como subsector con un peso específico - y excesivo - dentro del sector de la construcción. En todo caso, su evolución ha ido pareja, lógicamente, a la de esta rama de actividad. Así, la información de que se dispone sobre licencias otorgadas y viviendas terminadas refleja una caída muy importante de la construcción de vivienda nueva, tanto libre como protegida. En cuanto a su rehabilitación, las cifras referidas al número de viviendas sobre las que se han autorizado este tipo de intervenciones han sufrido vaivenes desde 2007. En el actual contexto, las transacciones inmobiliarias - operaciones de compraventa de viviendas - han disminuido enormemente, como también ha caído el precio de la vivienda, que sigue alcanzando niveles mínimos un mes tras otro ${ }^{4}$.

En fin, en lo que se refiere a la vivienda en alquiler, este mercado sigue teniendo en España muy poco peso en relación con el de venta. En este sentido, las viviendas en alquiler representan sólo el 16,9 \% del parque de vivienda de nuestro país, una cifra muy pequeña en comparación con otros países de nuestro entorno, en los que aquellas representan porcentualmente en torno al $33 \%$ del total de viviendas. Asimismo, si se atiende al dato de la población que reside en viviendas alquiladas, se observa que en nuestro país sólo el $17 \%$ vive en una vivienda en régimen de alquiler, frente a la media de la Unión Europea que se aproxima al $30 \%{ }^{5}$. En lo que respecta al precio de la vivienda en régimen de alquiler también ha sufrido caídas importantes desde el estallido de la crisis inmobiliaria, tanto en el conjunto del Estado, como en Andalucía 6 .

Toda esta información pone de manifiesto que el modelo productivo en el que se ha sustentado el sector de la construcción y la vivienda se encuentra hoy agotado. Los problemas de los que adolece el sector, en cuanto derivados de un modelo fuertemente consolidado, tienen, por tanto, carácter estructural y no coyuntural.

\footnotetext{
${ }^{3}$ Vid. la información estadística que facilita la página web del Ministerio de Fomento sobre construcción (construcción de edificios y obras en edificación) http://www.fomento.gob.es/.

${ }^{4}$ Vid. la información estadística que facilita la página web del Ministerio de Fomento sobre construcción (construcción de edificios) y vivienda y actuaciones urbanas (vivineda protegida, vivienda libre, transacciones inmobiliarias y precio de la vivienda) http://www.fomento.gob.es/.

5 Datos recogidos en el Plan de infraestructuras, transporte y vivienda $(2012$ - 2024). Documento para presentación institucional y participación pública. Ministerio de Fomento. Pág. III.2 y 10 http://www.fomento.gob.es/. Vid. asimismo, Preámbulo de la Ley 4/2013, de 4 de junio, de medidas de flexibilización y fomento del mercado del alquiler de viviendas.

${ }^{6}$ Así se deduce del contenido del Informe de la vivienda en alquiler en España correspondiente al tercer trimestre de 2014. Fotocasa. http://prensa.fotocasa.es. Los datos se refieren al precio de alquiler de la vivienda libre.
} 
En efecto, una actividad basada casi exclusivamente en la creación de nueva ciudad, y particularmente en la ampliación del parque residencial mediante la construcción de vivienda nueva para su venta - el parque de vivienda actual suma aproximadamente 26 millones, un $23 \%$ superior al existente en $2001^{7}$ - ha generado unos efectos devastadores desde el punto de vista económico, social y ambiental, siendo así que, además, no se deduce atisbo alguno recuperación a corto plazo. Todo ello impone la necesidad de reconvertir el sector de la construcción y la vivienda.

Para ello, es necesario que las políticas urbanas adopten una perspectiva de futuro, aportando soluciones dirigidas a evitar que vuelva a incurrirse en errores cometidos en el pasado. El urbanismo de expansión, de crecimiento urbano ilimitado, propició prácticas profundamente insostenibles que han generado enormes impactos. Por ello, en primer término, las políticas sobre suelo, construcción y vivienda deben tratar de definir un modelo de ciudad basado en criterios de sostenibilidad, que garantice la calidad de vida de los ciudadanos, sin comprometer la de las generaciones futuras, y resuelva los desequilibrios generados por el anterior modelo. $\mathrm{Al}$ respecto, como se verá a continuación, las instituciones internacionales y comunitarias vienen perfilando desde hace años ese modelo de ciudad sostenible: la ciudad compacta. Sobre ese modelo, al que nos referiremos en primer lugar, ha de sustentarse todo el proceso de reconversión del sector de la construcción y la vivienda.

Precisamente uno de los aspectos nucleares de ese modelo de ciudad sostenible es la priorización de la recuperación y la dinamización de la ciudad existente frente a los nuevos crecimientos urbanos. Esa idea se erige, pues, en piedra angular sobre la que debe sustentarse la recuperación de la actividad de la construcción, y así, las acciones que se emprendan para ello habrán de ir dirigidas a la regeneración y renovación del tejido urbano, la rehabilitación de edificios y el fomento del alquiler del parque residencial existente.

Estas son justamente las directrices que, en la actual coyuntura y comprobadas las carencias del actual modelo productivo del sector de la construcción, propone el Ministerio de Fomento. En este sentido, el Plan de Infraestructura, Transporte y Vivienda que ha elaborado el Ministerio para el horizonte 2012-2024 (en adelante, PITVI) señala como líneas directrices de las nuevas políticas en materia de urbanismo, vivienda y suelo, las siguientes:

- Transitar desde un urbanismo centrado en el desarrollo y el crecimiento de la ciudad hacia otro que tenga como meta esencial la regeneración y el reciclaje

${ }^{7}$ Plan de infraestructuras, transporte y vivienda (2012 - 2024) del Ministerio de Fomento, pág. III.5 
del espacio urbano y la sostenibilidad. A este respecto, entre los propósitos del Ministerio en este ámbito se encuentran mejorar las condiciones de los tejidos urbanos ya existentes y promover la regeneración urbana integrada de barrios completos.

- Pasar de unas políticas de suelo que han favorecido el monocultivo residencial hacia otras que fomenten la innovación, las actividades productivas, el desarrollo económico y la competitividad

- Cambiar una cultura de acceso a la vivienda vinculada a la propiedad por otra que tenga en el alquiler una opción deseable y preferente.

- Reorientar el sector basculando su actividad desde la construcción de vivienda nueva hacia la rehabilitación de viviendas y edificios ${ }^{8}$.

Se trata, en definitiva, de recuperar la actividad mediante su reconversión hacia formas de actuación más sostenibles, que se ajusten a la realidad actual de la construcción y la vivienda y resuelvan los desequilibrios generados por el modelo de expansión urbana y creación de vivienda nueva.

De conformidad con ello, el conjunto de las Administraciones Públicas - particularmente la estatal y la autonómica - viene trabajando en la creación de un nuevo marco normativo que persigue la consecución de ese objetivo. A este respecto, el PITVI refiere como fines de la actividad normativa emprendida los siguientes:

- Favorecer el desarrollo de un mercado del alquiler eficiente y asequible para las familias, especialmente las que tienen mayores dificultades en el acceso a la vivienda y los jóvenes,

- Incentivar la actividad de reforma y rehabilitación de viviendas y edificios, así como la regeneración urbana, en coordinación con las comunidades autónomas,

- Impulsar la actividad del sector, eliminando trabas o requisitos innecesarios,

- Acelerar el proceso de saneamiento del sector, en concreto la absorción del stock de vivienda nueva sin vender como requisito previo para su normalización y retomar la actividad.

Así pues, regeneración y renovación urbana, rehabilitación y fomento del alquiler de viviendas constituyen los pilares sobre los que deben asentarse las políticas sobre construcción y vivienda que adopten las Administraciones Públicas y entidades vinculadas en los próximos años. Todas esas líneas de actuación serán analizadas en las páginas siguientes, tomando en consideración los instrumentos normativos adoptados en relación con las mismas.

\footnotetext{
${ }^{8}$ PITVI, pág. III. 18
} 
Pero estimamos que junto éstas, existe otra cuestión que, a nuestro juicio, constituye un elemento importante a considerar por las nuevas políticas urbanas sobre construcción, suelo y vivienda.

Nos referimos a la existencia de miles de edificaciones y parcelaciones ilegales en el conjunto del territorio español, una realidad que no ha sido aún abordada adecuadamente por los poderes públicos. Durante los años del urbanismo feroz, de la expansión urbanizadora y residencial desmedida, las Administraciones han mostrado una enorme pasividad en el ejercicio de control de las actuaciones urbanísticas ejecutadas al margen de la legalidad, circunstancia que ha permitido su consolidación y generado problemas que, por la importancia de los intereses y derechos implicados, resulta difícil de tratar.

Como se ha señalado en las páginas anteriores, en el presente momento se asiste a una paralización de toda actividad de construcción dirigida a la creación de nueva ciudad, y se preconiza una reconversión que oriente tal actividad hacia el tejido urbano y residencial existente. Pues bien, de ese tejido forman parte también las actuaciones urbanísticas ejecutadas ilegalmente que frecuentemente se hallan en una situación de suma inseguridad jurídica. Cabe plantear la posibilidad de que, según los casos, dichas actuaciones puedan ser objeto de procesos de normalización o regularización dirigidos a clarificar el régimen que les son aplicables. Estos procesos exigen, en muchos casos, la ejecución obras de ajuste de los edificios o de reurbanización del entorno en el que se sitúan, intervenciones que se realizan, por tanto, sobre el medio urbano existente. De este modo, las operaciones regularizadoras se ajustan plenamente a las nuevas orientaciones de las políticas urbanas. Esta cuestión será también abordada en el presente trabajo.

\section{LAS NUEVAS DIREGTRICES DE LAS POLÍTICAS SOBRE GONSTRUGCIÓN Y VIVIENDA}

Una vez descrita la situación del sector de la construcción de la vivienda y apuntadas las pautas para su reconversión, en las paginas siguientes se profundizará sobre las mismas, teniendo en cuenta las medidas normativas que al respecto vienen adoptando los poderes públicos estatales y autonómicos.

\section{Hacia un desarrollo sostenible. La ciudad compacta}

En el actual contexto de crisis del ramo de la construcción, se dan las condiciones idóneas para una reflexión profunda sobre el modelo de crecimiento urbano que se ha seguido en nuestro país durante los años de bonanza de aquel sector. En este sentido, el urbanismo de crecimiento disperso predominante en España - que fue ya ob- 
jeto de duras críticas desde la Unión Europea, a través de documentos como por ejemplo el denominado informe Auken ${ }^{9}$ - ha generado, según se expuso anteriormente, enormes impactos, no sólo desde el punto de vista económico, sino también desde la óptica ambiental y social. Por tal motivo, y a fin de evitar errores del pasado, las políticas sobre suelo, construcción y vivienda deben apostar por un modelo de ciudad basado en pautas más sostenibles.

A este respecto, el modelo de ciudad al que deben orientarse esas políticas viene siendo definido a través de un número importante instrumentos internacionales y, sobre todo, comunitarios, en un proceso que se inició ya hace más de 20 años. La construcción de ese modelo se sustenta en la aplicación de un concepto que se halla en continua evolución, como es el de desarrollo sostenible, a las políticas urbanas.

El concepto de desarrollo sostenible, basado en los tres pilares: ambiental, económico y social, está presente hoy, por su carácter transversal, en todas las políticas públicas, y ha encontrado campo abonado para su aplicación en la planificación de la ciudad, configurándose a partir de esta conexión la idea de desarrollo urbano sostenible.

Entre los instrumentos que, en el plano internacional, han contribuido a la configuración de este último concepto y, consecuentemente, de un modelo de ciudad sostenible, cabe destacar la llamada Agenda 21, elaborada en el marco de la Cumbre de las Naciones Unidas de Río de 1992 y la carta Aalborg de 1994. En el ámbito comunitario, son muchos los documentos que han coadyuvado a perfilar el concepto de desarrollo urbano sostenible: el Libro Verde de 1990 sobre el medio ambiente urbano; el informe "Ciudades Europeas Sostenibles" (1996); las Comunicaciones elaboradas por la Comisión de la Unión Europea en los años 1997, "Hacia una política urbana de la Unión Europea", y 1998, "Marco de actuación para el desarrollo urbano sostenible de la Unión Europea"; la Estrategia Territorial Europea (1999); las comunicaciones "Hacia una estrategia temática sobre medio ambiente urbano" (2004) y "Una estrategia temática para el medio ambiente urbano" (2006); la Carta de Leipzig sobre la Ciudad Europea Sostenible (2007) y, por último, el informe de la Comisión "Ciudades del mañana: retos, visiones y caminos a seguir" (2011).

\footnotetext{
${ }^{9}$ Informe sobre el impacto de la urbanización extensiva en España en los derechos individuales de los ciudadanos europeos, el medio ambiente y la aplicación del Derecho comunitario, con fundamento en determinadas peticiones recibidas (2008/2248 INI). Recibe el nombre "Auken" por ser éste el apellido de la ponente del Informe.
} 
Toda la sucesión de documentos a que se acaba de hacer referencia han terminado por definir un modelo de ciudad sostenible que puede identificarse con el de ciudad compacta.

Se trata, de conformidad con las orientaciones contenidas en los instrumentos antes referidos, de un modelo de ciudad de alta densidad, policéntrica, y en la que se da primacía a la rehabilitación y renovación de la ciudad existente frente a nuevos crecimientos. Este modelo se opone al de ciudad difusa o de urbanización dispersa, extendido en Europa - y muy significativamente en España - y que ha demostrado ser altamente insostenible desde el punto de vista económico, social y ambiental.

Desde una perspectiva económica, no cabe duda de que la elección del modelo de ocupación de suelo tiene repercusión en los presupuestos públicos. En el caso de la ciudad difusa, la opción por este modelo, caracterizado por la dispersión en la ocupación y la baja densidad, trae consigo la necesidad de realizar fuertes inversiones para construir dotaciones, infraestructuras de transporte y kilómetros de viario al servicio de las nuevas urbanizaciones. Asimismo, exige ejecutar onerosas operaciones de conexión con las redes urbanas de saneamiento, de suministro de agua, electricidad, telefonía, telecomunicaciones, etc. Y por último, a los costes generados por todas estas actuaciones habrá que ir añadiendo los de su mantenimiento, una vez que las urbanizaciones son recepcionadas por los municipios. Todo ello hace de la ciudad difusa un modelo sumamente ineficaz desde el punto de visto económico.

Frente a ello, la elección de un modelo de ciudad compacta, densamente poblada, que apueste por la regeneración del tejido urbano y por la distribución racional de los espacios e infraestructuras públicos supondrá un uso más eficiente de los recursos económicos públicos.

Desde el punto de vista de la cohesión social, el modelo de ciudad difusa plantea también importantes inconvenientes. Por una parte, la generación de grandes bolsas de suelo aptos para la urbanización que sigue a la adopción de un modelo expansivo, lejos de determinar un menor precio de éste y, por tanto, de la vivienda, comporta un encarecimiento de ambos, como ha demostrado de forma incontestable la realidad inmobiliaria española de los últimos años. Se dificulta, con ello, la satisfacción del derecho a una vivienda digna. Por otra parte, los modelos expansivos suelen implicar polarización y uniformidad en la implantación de los usos urbanísticos y tipologías edificatorias (desde urbanizaciones residenciales de lujo a barrios de viviendas ultramasificadas), lo que potencia la segregación social. Por último, los modelos de baja densidad pueden complicar el acceso de los ciudadanos a los servicios públicos básicos en condiciones de proximidad, cuando la implantación de dotaciones se sujeta a parámetros como el número de habitantes o de viviendas. $\mathrm{O}$ en caso de que se construyan sin atender a estos criterios, se tratará de dotaciones sobredimensionadas y en absoluto desequilibrio en relación con las zonas urbanas más pobladas. 
De esta forma, un modelo de ciudad compacta en el que se promueva la mezcla de usos y de tipologías edificatorias y la igualdad en el acceso y disfrute de los servicios públicos resultará más sostenible desde la óptica de la cohesión social.

Finalmente, las mayores afecciones ambientales que provoca un modelo de urbanización expansivo, en relación con el de ciudad compacta, son evidentes. Así, en primer lugar, el modelo de ciudad difusa implica, obviamente, mayor ocupación de un recurso finito como es el suelo, que, además, por sus condiciones fisicas, no siempre es apto para acoger nuevos crecimientos urbanos, al margen de su más o menos evidente valor ambiental.

En segundo lugar, como se ha apuntado más arriba, los modelos de urbanización dispersa exigen la ejecución de un gran número de infraestructuras (redes de transporte, etc.) para la conexión de los nuevos crecimientos con la ciudad existente, lo que comporta la creación de barreras en los desplazamientos de las especies que afectan negativamente a la biodiversidad de los entornos urbanos.

En tercer lugar, el modelo de ciudad difusa incrementa la necesidad de uso de medios de transporte, y especialmente de vehículos privados, pues a más dispersión, mayor dificultad de conexión de los nuevos crecimientos con la ciudad mediante la red pública de transportes urbanos. Con ello, es claro, se incrementa el consumo de combustible y consecuentemente las emisiones a la atmósfera. $\mathrm{Al}$ mismo tiempo, la preferencia por el vehículo particular condiciona la configuración de la ciudad misma, que debe adecuarse a los requerimientos del tráfico rodado, con lo que se termina por afectar negativamente al paisaje urbano tradicional.

Así pues, el modelo de ciudad difusa causa un impacto sobre el medio ambiente urbano superior al que ocasiona el de ciudad compacta, que por su propia fisonomía supone un menor consumo de suelo, facilita la integración de los entornos naturales adyacentes a la ciudad y la conservación de la biodiversidad, y favorece la restricción del uso de los vehículos particulares.

Todos los anteriores razonamientos han determinado que la Unión Europea haya considerado el modelo de ciudad compacta como el más sostenible desde la triple óptica económica, social y ambiental. Ciertamente, los documentos que han permitido perfilar el modelo de ciudad sostenible tienen carácter indicativo, por la que la vinculación a sus contenidos por parte de los Estados miembros dependerá de su grado de compromiso con la sostenibilidad.

El principio de desarrollo urbano sostenible y el modelo de ciudad compacta, como no podía ser de otra manera, han tenido acogida en nuestras políticas públicas. En este sentido, en el plano estatal se han aprobado una diversidad de instrumentos 
que incorporan los criterios contenidos en los documentos anteriores - o que incluso son traslación de esos documentos al ámbito interno - Así, cabe destacar, entre otros, la Estrategia Española del Medio Ambiente Urbano, adoptada año 2006 por el Ministerio de Medio Ambiente y que transpone la Estrategia Temática Europea de Medio Ambiente Urbano; el Libro Blanco de la Sostenibilidad del Planeamiento (2010), y la Estrategia Española de Sostenibilidad Urbana y Local (2011). Por lo demás, la Comunidad andaluza también cuenta con su Estrategia Andaluza de Sostenibilidad Urbana.

En todo caso, todos estos documentos - políticas, programas, comunicaciones, estrategias- al igual que los procedentes de las instituciones internacionales y comunitarias, no dejan de ser instrumentos indicativos que se quedarían en meras declaraciones de intenciones si no se traducen en mandatos más concretos incorporados en normas jurídicamente vinculantes.

Y a este respecto, ha de señalarse que nuestro ordenamiento jurídico ha incorporado el buena parte de los postulados que derivan del concepto de desarrollo urbano sostenible. Así, el artículo 2 del TRLS de 2008 lo eleva a la categoría de principio rector de las políticas sobre suelo, al afirmar que: "las políticas públicas relativas a la regulación, ordenación, ocupación, transformación y uso del suelo tienen como fin común la utilización de este recurso conforme al interés general y según el principio de desarrollo sostenible, sin perjuicio de los fines específicos que les atribuyan las Leyes." El precepto, por lo demás, incorpora de manera explícita algunos de los elementos que caracterizan al modelo de ciudad sostenible propuesto por la Unión Europea. Particularmente, propugna:

- el uso racional de los recursos naturales que armonice los requerimientos de la economía, el empleo, la cohesión social, la igualdad de trato y de oportunidades entre mujeres y hombres, la salud y la seguridad de las personas y la protección del medio ambiente, $y$

- la consecución de un medio urbano suficientemente dotado que en el que se ocupe el suelo de manera eficiente, y en el que se combinen los usos de forma funcional, garantizando, en particular, la movilidad en coste y tiempo razonable, sobre la base de un adecuado equilibrio entre todos los medios de transporte; la accesibilidad universal; el uso eficiente de los recursos y de la energía, preferentemente de generación propia, así como la introducción de energías renovables; y la prevención y la minimización de los impactos negativos de los residuos urbanos y de la contaminación acústica.

El contenido de ese precepto se ve completado por lo dispuesto en el artículo 3 de la LRRRU, que establece los fines de las políticas públicas para un medio urbano más sostenible, eficiente y competitivo. Así, este último artículo profundiza en el modelo de ciudad sostenible, abundando en algunos de sus rasgos característi- 
cos: la mejora de la calidad y funcionalidad de las dotaciones, servicios y las infraestructuras; la localización de actividades económicas generadoras de empleo estable; la integración en el tejido urbano de usos compatibles con la función residencial para contribuir al equilibrio de las ciudades y de los núcleos residenciales, favoreciendo la diversidad de usos; fomento de la rehabilitación y puesta en valor del patrimonio urbanizado y edificado con valor histórico o cultural, y promoción del uso de energías renovables.

La introducción de estas exigencias como principio rector de políticas públicas constituye un avance importante. Es necesario, no obstante, un compromiso con la asunción de las mismas por parte de las Administraciones titulares de competencias con incidencia en la construcción de ciudad - especialmente territoriales y urbanísticas - a fin de que esos mandatos genéricos que constituyen los principios jurídicos se traduzcan en medidas concretas, reales, a implantar a través de los instrumentos de planificación territorial y, sobre todo, urbanísticos.

\section{Regeneración y renovación del tejido urbano y rehabili- tación edificatoria}

Como señala literalmente el PITVI, "la recuperación de la actividad pasa por una reconversión de la misma hacia formas de actuación más sostenibles a medio plazo, menos sustentadas en la construcción de nueva ciudad y más orientadas a la regeneración de la ciudad consolidada. "Y para ello, es necesario "ofrecer un marco normativo idóneo para permitir la reconversión y reactivación del sector de la construcción, encontrando nuevos ámbitos de actuación, en concreto, en la rehabilitación." $" 10$

Ese marco normativo viene constituido por la Ley 8/2013, de 26 de junio, de rehabilitación, regeneración y renovación urbana (en adelante, LRRRU). Esta disposición normativa establece el régimen básico de las actuaciones de rehabilitación edificatoria y de regeneración y renovación del tejido urbano existente, diseñando un estatuto elemental que se orienta a la consecución de un "desarrollo sostenible, competitivo $y$ eficiente del medio urbano."11

La Ley engloba todas estas intervenciones bajo el concepto "actuaciones sobre el medio urbano", que define como "aquéllas que tienen por objeto realizar obras de rehabilitación edificatoria, cuando existan situaciones de insuficiencia o degradación de los requisitos básicos de funcionalidad, seguridad y habitabilidad de las edificaciones, y de regeneración y renovación ur-

\footnotetext{
${ }^{10}$ PITVI, págs. III.20 y III.21

11 Art. 1 de la LRRRU.
} 
banas, cuando afecten, tanto a edificios, como a tejidos urbanos, pudiendo llegar a incluir obras de nueva edificación en sustitución de edificios previamente demolidos." 12 Se trata de una definición imprecisa de estas actuaciones que, no obstante, y a afectos de una reglamentación más completa, es reconducible a los tipos de actuaciones de transformación urbanística y edificatorias que regula el Texto Refundido de la Ley del Suelo, aprobado por Real Decreto Legislativo 2/2008, de 20 de junio (en adelante, TRLS) ${ }^{13}$.

En este sentido, en lo que hace a las actuaciones que tienen por objeto la regeneración o reconversión del tejido urbano existente, a efectos del TRLS, éstas pueden encajarse en las de reforma o renovación de la urbanización y en las de de dotación, reguladas en dicho texto legal.

Las primeras son, de acuerdo con esa norma, las que tienen por objeto reformar o renovar la urbanización de un ámbito de suelo urbanizado para crear, junto con las correspondientes infraestructuras y dotaciones públicas, una o más parcelas conectadas funcionalmente con la red de los servicios urbanos ${ }^{14}$. Por su parte, se entiende por actuaciones de dotación las que tienen por objeto "incrementar las dotaciones públicas de un ámbito de suelo urbanizado para reajustar su proporción con la mayor edificabilidad o densidad o con los nuevos usos asignados en la ordenación urbanística a una o más parcelas del ámbito y no requieran la reforma o renovación de la urbanización de éste. "15

En cuanto a las actuaciones sobre el medio urbano que, de conformidad con la LRRRU, tienen por objeto la rehabilitación de edificios, es evidente que integran las que el TRLS denomina de "rehabilitación edificatoria". De conformidad con esa disposición, estas actuaciones consisten en "la realización de las obras y trabajos de mantenimiento o intervención en los edificios existentes, sus instalaciones y espacios comunes, en los términos dispuestos por la Ley 38/1999, de 5 de noviembre, de Ordenación de la Edificación."16

La iniciativa para proponer la ordenación de actuaciones de rehabilitación edificatoria y de regeneración y renovación urbana corresponde, según la LRRRU, tanto a las Administraciones Públicas y las entidades adscritas o dependientes de las mis-

\section{Art. 7 de la LRRRU.}

${ }^{13}$ La LRRRU regula, como decimos, algunos aspectos elementales de la ordenación y gestión de las denominadas actuaciones sobre el medio urbano. No obstante, se trata de un régimen básico que requiere el complemento de otras disposiciones, como la Ley estatal de suelo - a efectos, por ejemplo, de valoraciones del suelo y los edificios - y sobre todo de la leyes y normas urbanísticas de las Comunidades Autónomas.

14 Art. 14.1.a.2) del TRLS.

${ }^{15}$ Art. 14.1.b) del TRLS.

${ }^{16}$ Art. 14.2.b) del TRLS. 
mas, como a propietarios, en concreto: comunidades o agrupaciones de comunidades de propietarios, cooperativas de vivienda constituidas al efecto, propietarios de terrenos, construcciones, edificaciones y fincas urbanas, titulares de derechos reales o de aprovechamiento, y las empresas, entidades o sociedades que intervengan en nombre de cualesquiera de los sujetos anteriores ${ }^{17}$.

Propietarios y Administraciones Públicas son, igualmente, los sujetos obligados a la ejecución de las obras comprendidas en estas actuaciones de regeneración, renovación y rehabilitación. En el caso de las Administraciones, quedan obligadas a la realización de tales obras cuando afecten a elementos propios de la urbanización y no exista el deber legal para los propietarios de asumir su coste, o cuando financien parte de la operación con fondos públicos, en los supuestos de ejecución subsidiaria, a costa de los obligados ${ }^{18}$.

El desarrollo de estas actuaciones va a requerir en muchas casos la previa innovación del planeamiento urbanístico, lo que habrá de realizarse siguiendo los trámites que al efecto prevén la leyes urbanísticas, en el caso de Andalucía, la Ley 7/2002, de 17 de diciembre, de Ordenación Urbanística de Andalucía (en adelante, LOUA). En todo caso, será preciso delimitar y aprobar un ámbito de actuación conjunta, que podrá ser continuo o discontinuo, o, en su caso, identificar la actuación aislada que corresponda $^{19}$.

En relación con lo anterior, cabe señalar que la Ley 1/2010, de 8 de marzo, reguladora del Derecho a la Vivienda en Andalucía, prevé la posibilidad de que las Administraciones andaluzas delimiten ámbitos de actuación regeneradora o rehabilitadora del tejido urbano. Se trata de las denominadas áreas de rehabilitación integral de barrios y centros históricos ${ }^{20}$, para cuya ejecución la Administración de la Junta de Andalucía, los municipios y otras Administraciones implicadas pueden convenir el establecimiento de las áreas de gestión integradas que regula la LOUA. Estas últi-

${ }^{17}$ Artículo 9 de la LRRRU. Con independencia de que la iniciativa para la ordenación de estas actuaciones puede ser privada, el apartado segundo de ese precepto señala que las Administraciones Públicas deben adoptar medidas que aseguren la realización de las obras de conservación, y la ejecución de actuaciones de rehabilitación edificatoria, de regeneración y renovación urbanas que sean precisas cuando existan situaciones de insuficiencia o degradación de los requisitos básicos de funcionalidad, seguridad y habitabilidad de las edificaciones; obsolescencia o vulnerabilidad de barrios, de ámbitos, o de conjuntos urbanos homogéneos; o situaciones graves de pobreza energética.

${ }^{18}$ Art. 8 de la LRRRU.

${ }^{19}$ Art. 10 de la LRRRU.

${ }^{20}$ Art. 18 de la Ley reguladora del Derecho a la Vivienda en Andalucía. Asimismo, estas Áreas fueron previstas por el Plan concertado de vivienda y suelo de Andalucía 2008-2012, que se encuentra ahora mismo en vigor. Sobre ellas se volverá más adelante. 
mas son, de conformidad con esa norma, ámbitos de actuación conjunta de las Administraciones que la constituyen, que asumen la obligación de coordinar e integrar las acciones que se desarrollen para la consecución de los objetivos perseguidos ${ }^{21}$ en el caso de las áreas de rehabilitación integral, la regeneración y renovación del tejido urbano existente ${ }^{-}$.

Sobre el contenido del acuerdo por el que se delimitan estos ámbitos, la LRRRU exige que incluya, como mínimo, un avance de la equidistribución, entre todos los afectados, de los costes derivados de la ejecución de la actuación proyectada, y, en su caso, el plan de realojo temporal y definitivo, y de retorno a que dé lugar ${ }^{22}$. Por lo demás, su adopción comporta la declaración de utilidad pública o interés social a efectos expropiatorios y de venta y sustitución forzosa de los bienes y derechos necesarios para la ejecución de la actuación, y legitima la ocupación de espacios libres o de dominio público de titularidad municipal que sean indispensables para la instalación de elementos que garanticen la accesibilidad universal ${ }^{23}$.

Por último, la ejecución de las actuaciones sobre el medio urbano reguladas en la LRRRU puede desarrollarse a través de cualquiera de las modalidades de gestión directa e indirecta previstas en la legislación sobre régimen jurídico, contratación pública y ordenación territorial o urbanística ${ }^{24}$. Por tanto, pueden participar en dicha actividad de ejecución, además de las Administraciones y las entidades vinculadas a ella, los propietarios o titulares de derechos afectados, en incluso entidades o sociedades que lo hagan por cualquier otro título ${ }^{25}$. A este respecto, la Ley prevé que cuando estas actuaciones sean de iniciativa pública, la Administración pueda adjudicar la ejecución de las obras por concurso público en el que pueden presentar ofertas cualesquiera personas físicas o jurídicas interesadas en asumir la gestión. Se abre la puerta, pues, a los promotores y constructores a la intervención en actuaciones de regeneración y renovación urbana y rehabilitación edificatoria. Una alternativa a la edificación de nueva planta y a la urbanización expansiva en que se ha sustentado el modelo productivo del sector de la construcción. Ello, en línea con el objetivo de reconvertir y recuperar esta rama de actividad.

Estos son, en esencia, los elementos básicos del régimen jurídico de las actuaciones que tengan por objeto la regeneración y renovación del tejido urbano existente y la rehabilitación de las edificaciones. Las líneas trazadas por la LRRRU habrán de

\footnotetext{
${ }^{21}$ Arts. 144 a 147 de la LOUA.

22 Art. 10 de la LRRRU.

${ }^{23}$ Art. 12 de la LRRRU.

${ }^{24}$ Art. 13 de la LRRRU.

25 Artículo 15 de la LRRRU
} 
ser seguidas, por tanto, por las políticas públicas que incorporen tales objetivos y también por los proyectos que pretenda desarrollar la iniciativa privada.

En relación con las políticas públicas, ha de indicarse que los más recientes planes de vivienda nacional y autonómico - éste último aún en proceso de aprobación - incorporan y concretan en sus programas las directrices trazadas por la LRRRU. Así, como se verá más adelante, buena parte de éstos se dirigen a la promoción de actuaciones de rehabilitación de edificios residenciales.

Pero estos nuevos planes contienen, además, otros programas que no tienen por objeto - o al menos no por objeto exclusivo - la vivienda, sino que persiguen la recuperación o regeneración del tejido urbano en el que aquellas se integran junto con edificios destinados a usos distintos, dotaciones y otros elementos que conforman un entorno urbano determinado y delimitado.

Así, el Plan Estatal de fomento del alquiler de viviendas, la rehabilitación edificatoria, y la regeneración y renovación urbanas, 2013-2016 ${ }^{26}$, regula dos programas que se orientan a la consecución del fin definido en el párrafo precedente: el programa de fomento de la regeneración y renovación urbanas y el programa para el fomento de ciudades sostenibles y competitivas.

En lo que respecta al primero, su rúbrica anuncia ya que este programa se enmarca plenamente en las directrices y objetivos de la LRRRU. En efecto, su objeto no es otro que "la financiación de la realización conjunta de obras de rehabilitación en edificios y viviendas, de urbanización o reurbanización de espacios públicos y, en su caso, de edificación en sustitución de edificios demolidos, dentro de ámbitos de actuación previamente delimitados"; obras que se realizarán "con la finalidad de mejorar los tejidos residenciales, y recuperar funcionalmente conjuntos históricos, centros urbanos, barrios degradados y núcleos rurales. $" 27$

Las actuaciones que tienen acceso a las subvenciones contempladas para este programa son las siguientes: la ejecución de obras o trabajos de mantenimiento e intervención en edificios y viviendas, instalaciones fijas, equipamiento propio y elementos comunes; la ejecución de obras de mejora de la calidad y sostenibilidad del medio urbano tales como obras de urbanización y reurbanización material de los espacios públicos, de mejora de la accesibilidad de los espacios públicos y destinadas a mejorar la eficiencia ambiental en materia de agua, energía, uso de materiales, gestión de residuos y protección de la biodiversidad; y obras de demolición y edificación de vi-

26 Aprobado por Real Decreto 233/2013, de 5 de abril.

27 Art. 25 del Plan estatal de vivienda. 
viendas de nueva construcción que tendrán que tener una eficiencia energética mínima B y cumplir las exigencias del Código Técnico de Edificación ${ }^{28}$.

Por lo demás, el acceso a las ayudas previstas - de la que pueden beneficiarse tanto Administraciones como propietarios de edificios de viviendas afectados - requiere que los ámbitos de actuación de actuación que se definan cumplan determinadas condiciones. Particularmente, que comprendan al menos 100 viviendas - salvo si se delimitan en cascos históricos, núcleos rurales o las actuaciones a desarrollar son exclusivamente de renovación urbana (y otros supuestos excepcionales), en cuyo caso el número de viviendas podrá ser inferior - y que al menos un $60 \%$ de la edificabilidad sobre rasante existente tenga como destino el uso residencial de vivienda habitual ${ }^{29}$.

En cuanto al programa para el fomento de ciudades sostenibles y competitivas, éste persigue también la promoción de actuaciones de regeneración de tejidos urbanos existentes, pero que formen parte de proyectos de especial trascendencia, basados en alguna de las líneas estratégicas temáticas siguientes: mejora de barrios (tejidos de bloques construidos entre 1940 y 1980); centros y casos históricos; renovación de áreas funcionalmente obsoletas; renovación de áreas para la sustitución de infravivienda; ecobarrios (impulso de la sostenibilidad ambiental en los edificios y en los espacios públicos), y zonas turísticas ${ }^{30}$.

Los beneficiarios, en este caso, pueden ser también las Administraciones y los propietarios de edificios de viviendas incluidos en el ámbito de actuación.

Hasta aquí el análisis de los programas sobre regeneración urbana contenidos en el vigente Plan estatal de vivienda. El Plan marco de vivienda y rehabilitación de Andalucía - aún en elaboración - también incorpora instrumentos y programas que tienen por objeto técnicas y actuaciones de recuperación del tejido urbano. Como se acaba de señalar, no es un Plan aprobado ni concluido en su configuración, pero en todo caso introduce ya con toda claridad su principales líneas de acción. Con independencia de ello, el Plan concertado de vivienda y suelo 2008-2012, actualmente vigente hasta tanto no se apruebe y publique el Plan marco, ya prevé instrumentos dirigidos a la regeneración urbana.

Así, en este instrumento se regulan las áreas de rehabilitación de barrios y centros históricos, identificados ahora en la Ley del Derecho a la Vivienda en Andalucía y a las que hemos hecho alusión antes. Según el Plan concertado, las áreas de rehabilitación

${ }^{28}$ Art. 26 del Plan estatal de vivienda.

${ }^{29}$ Arts. 27 y 28 del Plan estatal de vivienda.

30 Art. 38 del Plan estatal de vivienda. 
constituyen un instrumento global para la rehabilitación integral de ámbitos urbanos, centrales o periféricos, afectados por problemas habitacionales, con el objetivo de mejorar las condiciones de alojamiento de la población y otros aspectos de carácter urbanístico, social y económico, mediante la integración, la coordinación y el fomento de las distintas actuaciones que los agentes públicos y privados puedan desarrollar en dichos ámbitos urbanos. En ellas pueden aplicarse cualesquiera programas contenidos en ese y otro plan autonómico y otros de regulación local, estatal o comunitaria ${ }^{31}$.

Junto a este instrumento, se regula otra figura denominada rehabilitación concertada de iniciativa municipal, a través de la cual pueden desarrollarse actuaciones de rehabilitación integral de ámbitos urbanos, gestionadas por sus respectivos Ayuntamientos, donde aplicar de manera complementaria a otras acciones de carácter físico y social los distintos programas incluidos en el Plan $^{32}$.

El borrador de Decreto por el que se aprueba el Plan marco de vivienda y rehabilitación de Andalucía incorpora también, como hemos dicho, instrumentos dirigidos a promocionar la recuperación de los entornos urbanos. Se contienen en el capítulo denominado "Rehabilitación de la ciudad", y las figuras comprendidas en él cuentan con una regulación más extensa, precisa, y adaptada la actuales necesidades que las que incluyen en el Plan concertado de 2008. Algunas de ellas se vinculan, como veremos, a las descritas anteriormente del Plan estatal.

En primera lugar, el Plan marco establece una nueva regulación de las referidas áreas de rehabilitación integral. Según el Plan, éstas han de delimitarse en ámbitos urbanos en los que se concentren procesos de segregación y graves problemas de carácter habitacional que afecten a sectores de población en riesgo de exclusión social, y las actuaciones que se desarrollen en ellos han de tener como objetivo principal invertir los procesos de degradación urbana y residencial, favoreciendo la integración en la ciudad, la cohesión social y el desarrollo económico del ámbito de actuación ${ }^{33}$.

En los ámbitos que se proponga delimitar han de concurrir una serie de circunstancias: uso predominantemente residencial, avanzado deterioro urbano, degradación del parque residencial y necesidad de mejora de las condiciones sociales de la población ${ }^{34}$. Por lo demás, la gestión de estos ámbitos perseguirá la coordinación entre los agentes públicos y privados intervinientes ${ }^{35}$, y en cuanto a su financiación,

\footnotetext{
31 Arts. 93 a 97 del Plan concertado de vivienda y suelo 2008-2012.

32 Arts. 98 a 100 del Plan concertado de vivienda y suelo 2008-2012.

33 Art. 82 del borrador de Plan marco de vivienda y rehabilitación.

34 Art. 83 del borrador de Plan marco de vivienda y rehabilitación.

35 Art. 84 del borrador Plan marco de vivienda y rehabilitación.
} 
además de nutrirse de recursos aportados por las Junta de Andalucía, las actuaciones que se desarrollen en el seno de las áreas de rehabilitación integral podrán ser objeto de las ayudas previstas por el Plan estatal para el programa de fomento de la regeneración y renovación urbanas, al que, por tanto, se halla ligado ${ }^{36}$.

Otro de los instrumentos de fomento de la regeneración del tejido urbano de los contenidos en el Plan andaluz es el programa de rehabilitación urbana sostenible. Este instrumento tiene por objeto el desarrollo y financiación de proyectos específicos e integrales, que persiguen la reactivación de las potencialidades y oportunidades de mejora sostenible de las condiciones urbanas, residenciales, patrimoniales, sociales, económicas y ambientales de ámbitos urbanos, centrales o periféricos ${ }^{37}$. Las acciones que se propongan para el desarrollo de estos proyectos deben tener por objeto alguno de los siguientes fines: la mejora del espacio público; la rehabilitación y mejora energética de edificios residenciales; la provisión de equipamientos de uso colectivo, priorizando la rehabilitación de edificios de interés arquitectónico; el fomento de las sostenibilidad del medio ambiente urbano;la mejora de la accesibilidad y la movilidad sostenible; el desarrollo de programas para la mejora social; la incorporación de parámetros de igualdad de género en el medio urbano; la mejora de las condiciones económicas a través de actuaciones que fomenten el comercio y el turismo sostenibles ${ }^{38}$.

Como puede observarse, el contenido de este programa presenta notas comunes al de fomento de ciudades sostenibles y competitivas contenido en el Plan estatal de vivienda. - selección de proyectos que siguen una línea estratégica predeterminada -. De hecho, el Plan andaluz prevé expresamente que la financiación de los proyectos de rehabilitación urbana sostenible pueda complementarse mediante el acogimiento a dicho programa estatal ${ }^{39}$

Por último, el Plan marco incorpora un apartado denominado instrumentos de apoyo y fomento de la rehabilitación, que prevé diversas medidas de apoyo técnico y fomento de la rehabilitación (asesoramiento a los ciudadanos sobre la legislación específica, colaboración con Ayuntamientos, acciones formativas, reconocimiento público de ejemplos de buenas prácticas, etc.)

\footnotetext{
${ }^{36}$ Arts. 86 y 88 del borrador de Plan marco de vivienda y rehabilitación.

${ }^{37}$ Art. 89 del borrador de Plan marco de vivienda y rehabilitación.

${ }^{38}$ Art. 90 del borrador de Plan marco de vivienda y rehabilitación.

${ }^{39}$ Art. 94 del borrador de Plan marco de vivienda y rehabilitación.
} 
Estos son algunos de los instrumentos que, partiendo de las directrices trazadas por la LRRRU, han puesto en marcha las Administraciones estatal y autonómica para alcanzar los propósitos de la norma, concretamente los que no tienen por objeto exclusivo de acción la vivienda, a los que se hará referencia en el siguiente epígrafe. Con ellos persigue un doble objetivo: la mejora de la calidad de vida de los ciudadanos y la reactivación del sector de la construcción mediante la definición de actuaciones alternativas a las de nueva edificación y urbanización expansiva, en la que se ha sustentado esta rama de actividad hasta ahora y que la han llevado a su actual situación de crisis.

\section{Medidas específicas en materia de vivienda: rehabilita- ción y fomento de alquiler}

Ya se ha apuntado antes la importancia que dentro del sector de la construcción tiene el ámbito de la vivienda. Esa circunstancia determina que se aborden de manera singular los instrumentos que proporcionan las diferentes disposiciones normativas dirigidos a la recuperación - en términos sociales y económicos - de este mercado.

A este respecto, la especial sensibilidad y preocupación con que hay que abordar el problema de este subsector de la construcción, deriva del hecho de que la vivienda no es un bien o producto económico como cualesquiera otros que son objeto de transacción en los mercados. La vivienda constituye un aspecto esencial en la vida de las personas consagrado como derecho por instrumentos internacionales - así, la Declaración Universal de los Derechos Humanos ${ }^{40}$ y el Pacto Internacional de Derechos Económicos, Sociales y Culturales ${ }^{41}$ - por la Constitución y por el Estatuto de Autonomía de Andalucía.

${ }^{40} \mathrm{El}$ artículo 25.1 de la Declaración Universal de Derechos Humanos establece que "toda persona tiene derecho a un nivel de vida adecuado que le asegure, así como a su familia, la salud y el bienestar, y en especial la alimentación, el vestido, la vivienda, la asistencia médica y los servicios sociales necesarios; tiene asimismo derecho a los seguros en caso de desempleo, enfermedad, invalidez, viudez y otros casos de pérdida de sus medios de subsistencia por circunstancias independientes de su voluntad".

${ }^{41}$ De acuerdo con el párrafo 1 del artículo 11 del Pacto Internacional de Derechos Económi$\cos$, Sociales y Culturales, los Estados partes "reconocen el derecho de toda persona a un nivel de vida adecuado para sí y su familia, incluso alimentación, vestido y vivienda adecuados, y a una mejora continua de las condiciones de existencia. Los Estados partes tomarán medidas apropiadas para asegurar la efectividad de este derecho, reconociendo a este efecto la importancia esencial de la cooperación internacional fundada en el libre consentimiento". 
Así, la Constitución española, en su artículo 47, reconoce a todos los españoles el "derecho a disfrutar de una vivienda digna y adecuada" e insta a los poderes públicos a promover las condiciones necesarias y establecer las normas pertinentes para hacer efectivo este derecho, "regulando la utilización del suelo de acuerdo con el interés general para impedir la especulación." El derecho a la vivienda se configura como un principio rector de la política social y económica y, en consecuencia, conforme al artículo 53.3 del texto constitucional, su reconocimiento, respeto y protección informan la legislación positiva, la práctica judicial y la actuación de los poderes públicos.

En este marco, el Estatuto de Autonomía de Andalucía concreta el mandato constitucional dirigido a los poderes públicos de promover las condiciones necesarias para la efectividad del derecho a la vivienda, a la vez que potencia su contenido prestacional y lo liga con el principio de igualdad en el acceso a la vivienda. Así, el artículo 25 recoge el deber de los poderes públicos de realizar la promoción pública de vivienda, añadiendo que la Ley regulará el acceso a la misma en condiciones de igualdad, así como las ayudas que lo faciliten; y el artículo 37.1.22. ${ }^{\circ}$ establece como principio rector de las políticas públicas la promoción del acceso a la vivienda protegida de las personas que se encuentren dentro de los colectivos más necesitados ${ }^{42}$.

De acuerdo con lo anterior, es claro que los poderes públicos vienen obligados a adoptar medidas que faciliten el acceso a la vivienda a las personas. En un momento de especial dificultad como el presente, deben redoblarse los esfuerzos en la búsqueda de instrumentos que permitan garantizar la efectividad de este derecho.

Pero al margen de esta dimensión social, no cabe duda de que en torno a la vivienda se desarrolla una actividad económica de primer orden. Así, la rama de la vivienda tiene un peso enorme dentro de un sector en crisis como el de la construcción. De ahí la urgencia de hallar soluciones dirigidas, además de a garantizar el derecho a la vivienda, también a dinamizar este mercado, de modo que ello contribuya a la recuperación de aquel sector y de la economía en general, en la idea de que además, en una coyuntura más favorable en términos económicos y de empleo, se crearan condiciones más propicias para que los ciudadanos puedan acceder a una vivienda digna.

Así pues, en el marco de un proceso de reconversión del sector de la construcción, los poderes públicos deben adoptar medidas que contribuyan a revitalizar el mercado de la vivienda. Se trata de fomentar el desarrollo de actuaciones alternativas a la ejecución de nuevas viviendas, actividad en la que se ha apoyado casi exclusivamen-

${ }^{42}$ Exposición de motivos de la Ley del Derecho a la Vivienda en Andalucía. 
te el sector. A este respecto, como ya se ha avanzado, las líneas de acción que proponen las más recientes políticas de vivienda son la rehabilitación de edificios residenciales y el fomento del alquiler, instrumentos que aunque previstos en anteriores planes de vivienda, no han tenido el peso que habría sido deseable y que quizás habría evitado en alguna medida la aparición de una crisis tan severa como la que viene padeciendo el mercado residencial.

En este sentido, como apunta la exposición de motivos del borrador de Plan marco de vivienda y rehabilitación de Andalucía, "las políticas de vivienda de ámbito estatal y autonómico, concretadas para el último periodo a través del Plan Estatal de Vivienda y Rehabilitación 2009-2012 y el Plan Concertado de Vivienda y Suelo 2008-2012, no previeron en toda su dimensión las consecuencias sobrevenidas tras el estallido de la burbuja inmobiliaria y aunque apostaron por la rehabilitación y el alquiler del parque residencial existente, privilegiaron su apoyo a la construcción de nuevas viviendas destinadas a la venta."

Rehabilitación y fomento de alquiler son, por tanto, las líneas de acción que hay que priorizar para hallar una solución al mercado de la vivienda. Sobre ello se tratará en las páginas siguientes.

a) Rehabilitación de viviendas

Según afirma la exposición de motivos de la LRRRU, aproximadamente el $55 \%$ (13.759.266) del parque edificado español, que asciende a 25.208.622 viviendas, es anterior al año 1980 y casi el $21 \%$ (5.226.133) cuentan con más de 50 años. Parece evidente, por tanto, la necesidad de intervenciones de rehabilitación.

A este respecto, pese a la antigüedad del parque de viviendas, lo cierto es que el peso de la rehabilitación en el conjunto del sector de la construcción es pequeño. En este sentido, el porcentaje que representa la rehabilitación en España en relación con el total de la construcción es uno de los más bajos de la zona euro. Así, en 2009 la rehabilitación suponía un $28 \%$ del total del sector, porcentaje que se ha incrementado desde el 23\% registrado en 2007 pero que no debe considerarse como un incremento absoluto, ya que es sólo la consecuencia de la bajada de la inversión en nueva construcción, estando en todo caso la cifra muy alejada de la media europea, situada en el $41 \%{ }^{43}$.

Como ya hemos visto, el gobierno ha hecho una apuesta decidida por la rehabilitación mediante la LRRRU, que ofrece al sector de la construcción una alternativa

\footnotetext{
43 PITVI, págs. III. 10 y 11
} 
a la construcción de edificios de nueva planta, particularmente de viviendas. En el apartado anterior se ha analizado el régimen básico establecido por esa ley para las denominadas actuaciones sobre el medio urbano, que evidentemente tienen como uno de sus objetos preferentes a los edificios de uso residencial ${ }^{44}$. Las directrices trazadas por la LRRRU han sido concretadas por los más recientes planes en materia de vivienda, estatal y autonómico.

Así, por lo que respecta al Plan estatal, incorpora un programa de fomento de la rehabilitación edificatoria que tiene por objeto "la financiación de la ejecución de obras y trabajos de mantenimiento e intervención en las instalaciones fijas y equipamiento propio, así como en los elementos y espacios privativos comunes, de los edificios de tipología residencial colectiva". Para tener acceso a las ayudas previstas, es preciso que se trate de edificios terminados antes de $1981^{45}$.

El programa establece como subvencionables un gran número de actuaciones para la conservación de los edificios - cuando se detecten deficiencias a través del informe de evaluación -; para la mejora de la calidad y sostenibilidad de los edificios (mejora de la envoltura térmica, instalación de equipos de refrigeración y calefacción, instalación de sistemas que permitan la utilización de energías renovables, mejora de la eficiencia energética, etc.), y para realizar los ajustes razonables en materia de accesibilidad (instalación de ascensores, salvaescaleras, grúas, elementos de aviso, etc.) ${ }^{46}$

Por lo demás, pueden ser beneficiarios de estas ayudas las comunidades de propietarios, las agrupaciones de comunidades de propietarios, o los propietarios únicos de edificios de viviendas, así como las Administraciones Públicas y los organismos y demás entidades de derecho público, empresas públicas y sociedades mercantiles participadas íntegra o mayoritariamente por las Administraciones propietarias de los inmuebles (respecto de los que tengan como destino el alquiler durante, al menos, 10 años $)^{47}$.

\footnotetext{
${ }^{44}$ En este sentido, el artículo 3 de la LRRRU, entre otros, señala como fines de las políticas públicas para el medio urbano:

Posibilitar el uso residencial en viviendas constitutivas de domicilio habitual en un contexto urbano seguro, salubre, accesible universalmente, de calidad adecuada e integrado socialmente, provisto del equipamiento, los servicios, los materiales y productos que eliminen o, en todo caso, minimicen, por aplicación de la mejor tecnología disponible en el mercado a precio razonable, las emisiones contaminantes y de gases de efecto invernadero, el consumo de agua, energía y la producción de residuos, y mejoren su gestión.

Favorecer y fomentar la dinamización económica y social y la adaptación, la rehabilitación y la ocupación de las viviendas vacías o en desuso.

${ }^{45}$ Art. 19 del Plan estatal de vivienda.

${ }^{46}$ Art. 20 del Plan estatal de vivienda.

${ }^{47}$ Art. 22 del Plan estatal de vivienda.
} 
El Plan estatal también incorpora un programa de apoyo a la implantación del informe de evaluación de los edificios, cuyo objeto es el impulso a la generalización de este documento mediante una subvención que cubra parte de los gastos de honorarios profesionales para su emisión. Ésta instrumento, regulado en la LRRRU ${ }^{48}$, permite identificar las deficiencias e insuficiencias del edificio residencial, de modo que a través de la misma es posible determinar qué intervenciones rehabilitadoras han de llevarse a cabo.

En lo que respecta a la Comunidad andaluza, el vigente Plan concertado de vivienda y suelo 2008-2012 incluye ya medidas dirigidas a fomentar actuaciones rehabilitadoras o de mejora de la eficiencia energética en viviendas y edificios de viviendas.

Así, en primer lugar, el Plan incorpora una serie de programas que tienen por objeto el apoyo a la rehabilitación. En concreto:

- Transformación de la infravivienda ${ }^{49}$. Este programa tiene por objeto mejorar las condiciones de habitabilidad en zonas urbanas con núcleos de infravivienda, mediante la combinación de obras de rehabilitación, nueva planta, urbanización y trabajo social ${ }^{50}$.

- Rehabilitación autonómica. El objeto del Programa es ayudar a familias de recursos limitados que promuevan actuaciones de rehabilitación de sus viviendas en municipios declarados de rehabilitación autonómica ${ }^{51}$.

- Rehabilitación individualizada de viviendas. Su objeto es facilitar el acceso a la financiación cualificada - préstamo cualificado regulado en el propio Plan - a las familias que promuevan actuaciones de rehabilitación de sus viviendas ${ }^{52}$.

- Rehabilitación de edificios. Este programa fomenta la rehabilitación de los elementos comunes de los edificios residenciales, mediante la ayuda a comunidades de propietarios y propietarias de edificios de viviendas con recursos limitados y a personas propietarias de edificios de viviendas destinadas al alquiler ${ }^{53}$.

${ }^{48}$ Arts. 4 a 6.

${ }^{49}$ Según el artículo 2 de la LRRRU, se entiende por infravivienda "la edificación, o parte de ella, destinada a vivienda, que no reúna las condiciones mínimas exigidas de conformidad con la legislación aplicable. En todo caso, se entenderá que no reúnen dichas condiciones las viviendas que incumplan los requisitos de superficie, número, dimensión y características de las piezas habitables, las que presenten deficiencias graves en sus dotaciones e instalaciones básicas y las que no cumplan los requisitos mínimos de seguridad, accesibilidad universal y habitabilidad exigibles a la edificación."

${ }^{50}$ Arts. 74 a 77 del Plan concertado.

${ }^{51}$ Arts. 78 a 80 del Plan concertado.

52 Arts. 81 a 83 del Plan concertado.

53 Arts. 84 a 86 del Plan concertado. 
- Rehabilitación singular. Con este programa se pretende proteger y financiar otras actuaciones específicas en materia de rehabilitación no contempladas en los programas anteriores, así como la reparación de los daños causados en viviendas o edificios residenciales por fenómenos naturales sobrevenidos ${ }^{54}$.

- Adecuación funcional básica de viviendas. Este programa prevé ayudas destinadas a mejorar la seguridad y adecuación funcional de las viviendas que constituyan residencia habitual y permanente de personas mayores o personas con discapacidad ${ }^{55}$.

- Actuaciones sobre viviendas de titularidad pública. El programa tiene por objeto establecer mecanismos de colaboración entre la Administración de la Junta de Andalucía y los municipios para la reparación del parque público residencial $^{56}$

En segundo lugar, el Plan concertado incorpora un programa que tiene por objeto fomentar la utilización de energías renovables, la mejora de la eficiencia energética, la higiene, salud y protección del medio ambiente, así como la accesibilidad del parque residencial existente, mediante ayudas a las personas que promuevan la rehabilitación de sus viviendas o edificios de viviendas ${ }^{57}$

Así pues, como puede observarse, el Plan vigente dedica ya una parte importante de su contenido al fomento de la rehabilitación de viviendas. El nuevo Plan marco de vivienda y rehabilitación - del que todavía no existe más que un borrador - según se anuncia en su preámbulo, hace una apuesta decidida por la rehabilitación, pero tal apuesta debe de serlo en términos presupuestarios ${ }^{58}$, pues en lo que hace a los tipos de actuaciones contempladas, buena parte de ellas ya se prevén en el Plan concertado 2008-2012. No obstante, la regulación establecida en el borrador presenta diferencias respecto de la contenida del Plan anterior, ligadas a la actual situación económica y del mercado de la vivienda.

En primer lugar, en lo que respecta al parque público residencial de la Comunidad, el Plan marco prevé diversas medidas de fomento de la rehabilitación:

${ }^{54}$ Art. 87 del Plan concertado.

55 Art. 88 del Plan concertado.

56 Arts. 89 a 92 del Plan concertado.

${ }^{57}$ Arts. 92 bis y 92 ter del Plan concertado.

${ }^{58}$ A este respecto, en la exposición de motivos del borrador de Plan marco se indica que "la masiva demanda de las ayudas contempladas en el Plan Concertado de Vivienda y Suelo 2008-2012 para la rehabilitación de viviendas y edificios residenciales y el fomento del alquiler, que ha superado ampliamente su capacidad presupuestaria, ha puesto de relieve las necesidades de rehabilitación, mantenimiento, conservación y alquiler de este parque residencial." 
- Aprobación por la consejería competente en materia de vivienda de un plan de mejora y mantenimiento del parque público residencial de la Comunidad Autónoma de Andalucía ${ }^{59}$.

- Apoyo a la autorreparación por las personas arrendatarias de las viviendas que habitan y de los elementos comunes de los edificios que componen el parque público residencial ${ }^{60}$.

- Elaboración por la consejería competente en materia de vivienda de un programa de rehabilitación del parque público residencial que, entre otros extremos, podrá comprender: la eficiencia energética, orientada hacia la mejora de la envolvente térmica y de las instalaciones eléctricas de los edificios; la incorporación de equipos de generación, que permitan la utilización de las energías renovables, y la accesibilidad a las edificaciones ${ }^{61}$.

En segundo lugar, en el contexto de gran dificultad económica en el que se ven inmersas muchas familias andaluzas, el plan incluye un apartado específico sobre rehabilitación y cohesión social, que incorpora una regulación sobre la infravivienda y su transformación más extensa que la contenida en el Plan vigente.

Así, el Plan incluye un programa que tiene por objeto mejorar las condiciones de alojamiento en zonas urbanas caracterizadas por la concentración de infraviviendas, mediante la financiación de actuaciones de rehabilitación, promovidas por las personas residentes, que persigan su transformación en viviendas dignas y adecuadas ${ }^{62}$. Como es lógico, podrán ser personas beneficiarias de las ayudas de este programa las personas promotoras de las actuaciones sobre las infraviviendas que constituyan su residencia habitual y permanente ${ }^{63}$.

Por último, el borrador de Plan marco contiene un capítulo titulado "rehabilitación residencial" que contiene diversas medidas que tienen como finalidad la promoción de la rehabilitación de edificios destinados a vivienda:

- Rehabilitación, accesibilidad y eficiencia energética de los edificios. El programa tiene por objeto el fomento de la rehabilitación de edificios residenciales de vivienda colectiva con deficiencias en sus condiciones básicas, mediante la financiación de actuaciones que resulten necesarias para subsanarlas y mejorar su accesibilidad y eficiencia energética ${ }^{64}$.

\footnotetext{
${ }^{59}$ Art. 55 del borrador de Plan marco.

${ }^{60}$ Art. 56 del borrador de Plan marco.

${ }^{61}$ Art. 57 del borrador de Plan marco.

62 Art. 61 del borrador de Plan marco.

63 Art. 62 del borrador de Plan marco.

${ }^{64}$ Art. 70 del borrador de Plan marco.
} 
- Pueden ser entidades beneficiarias las comunidades de propietarios, que además podrán solicitar y obtener, de manera complementaria a las correspondientes a este programa, las ayudas del programa de fomento de la rehabilitación edificatoria previstas en el Plan estatal, al que se ha hecho referencia anteriormente ${ }^{65}$. También se prevén ayudas para la implantación del informe de evaluación de edificios ${ }^{66}$.

- Rehabilitación autonómica. El programa tiene el mismo objeto que el anterior, pero podrá desarrollarse en municipios que hayan sido declarados de rehabilitación autonómica y los beneficiarios en este caso serán las personas que promuevan las actuaciones en las viviendas que constituyan su residencia habitual y permanente ${ }^{67}$.

- Adecuación funcional básica de viviendas. Este programa tiene idéntico objeto al contemplado para el programa previsto con el mismo título en el programa concertado 2008-2012: mejorar la seguridad y adecuación funcional de las viviendas que constituyan residencia habitual y permanente de personas mayores o personas con discapacidad ${ }^{68}$.

Estas son, pues, las medidas para el fomento de la rehabilitación residencial previstas en los planes de vivienda estatal y autonómica. En el marco de los mismos podrán elaborar sus políticas las entidades locales, sin perjuicio de establecer otras con fines adecuados las específicas necesidades de la población incluido en su ámbito de acción.

\section{b) Fomento del alquiler}

En el primer apartado se ha hecho referencia al escaso peso que en nuestro país tiene el alquiler como forma de acceso a una vivienda. En este sentido, según se expuso antes, las viviendas en alquiler representan sólo el 16,9\% del parque de vivienda de nuestro país, y si se atiende al dato de la población que reside en viviendas alquiladas, se observa que en España sólo el $17 \%$ reside en una vivienda en régimen de alquiler. Por otra parte, según los datos del censo de población y viviendas 2011 que elabora el INE - nota de prensa de abril de 2013 -, en España existen 3.443.365 viviendas vacías, de las cuales, 637.221 se encuentran en Andalucía, donde el porcentaje de viviendas vacías respecto del total de viviendas representa el 14,6\% $\%$. ${ }^{69}$

65 Arts. 71 y 74 del borrador de Plan marco.

66 Art. 75 del borrador de Plan marco.

67 Arts. 76, 77 y 78 del borrador de Plan marco.

68 Art. 81 del borrador de Plan marco.

69 Información obtenida de la página web del Instituto Nacional de Estadística. Censo de población y vivienda 2011. http://www.ine.es/. 
Los datos anteriores son reveladores de la necesidad de adoptar, en un contexto de extrema dificultad para obtener crédito necesario para la adquisición en propiedad de una vivienda, medidas encaminadas a fomentar su alquiler. Como veremos en las páginas siguientes, parece que tanto la Administración estatal como la de la Comunidad andaluza han iniciado esa tarea a través de diversos instrumentos que pretenden incentivar, por un lado, la puesta en alquiler por sus propietarios del importante número de viviendas vacías y, por otro, que potenciales arrendatarios opten por esta forma de acceso a la vivienda.

Así, de una parte, el gobierno puso en marcha un proceso dirigido a flexibilizar el mercado del alquiler para lograr su dinamización; proceso que fructificó en la Ley 4/2013, de 4 de junio, de medidas de flexibilización y fomento del mercado del alquiler de viviendas. El núcleo fundamental de la norma es la modificación de una parte importante del contenido de la Ley de Arrendamientos Urbanos. La propia exposición de motivos de la Ley 4/2013 identifica los aspectos fundamentales de la reforma:

- El régimen jurídico aplicable, reforzando la libertad de pactos y dando prioridad a la voluntad de las partes, en el marco de lo establecido en el título II de la Ley de Arrendamientos.

- La duración del arrendamiento, reduciéndose de cinco a tres años la prórroga obligatoria y de tres a uno la prórroga tácita, con objeto de dinamizar el mercado del alquiler y dotarlo de mayor flexibilidad. De esta forma, arrendadores y arrendatarios podrán adaptarse con mayor facilidad a eventuales cambios en sus circunstancias personales.

- La recuperación del inmueble por el arrendador para destinarlo a vivienda permanente en determinados supuestos, que requiere que hubiera transcurrido al menos el primer año de duración del contrato, sin necesidad de previsión expresa en el mismo, dotando de mayor flexibilidad al arrendamiento.

- La previsión de que el arrendatario pueda desistir del contrato en cualquier momento, una vez que hayan transcurrido al menos seis meses y lo comunique al arrendador con una antelación mínima de treinta días. Se reconoce la posibilidad de que las partes puedan pactar una indemnización para el caso de desistimiento.

Estas medidas de flexibilización dirigidas a la dinamización del mercado del alquiler comportan, no obstante, desde el punto de vista del potencial arrendatario, una cierta desprotección respecto del régimen existente antes de la reforma, lo que podría suponer un desincentivo a esta forma de acceso a la vivienda que habría de ser compensada por otros mecanismos. A este respecto, resulta llamativo que, en el marco de un política que se dirige a fomentar el alquiler, el gobierno planee eliminar la deducción estatal por alquiler actualmente vigente a través de una futura Ley de 
reforma fiscal, cuyo Proyecto ha tenido ya entrada en las Cortes Generales ${ }^{70}$, siendo así que además el PITVI apuntaba precisamente a la fiscalidad como uno de los instrumentos importantes para impulsar la reconversión del sector de la vivienda ${ }^{71}$.

De otra parte, los más recientes planes de vivienda, estatal y autonómico, hacen una apuesta decidida por el fomento del alquiler.

En lo que respecta al Plan estatal, éste incorpora dos programas que tienen aquella finalidad: el programa de ayuda al alquiler de vivienda y el programa de fomento del parque público de vivienda en alquiler.

El primero de ellos tiene por objeto "facilitar el acceso y la permanencia en una vivienda en régimen de alquiler a sectores de población con escasos medios económicos" $" 72$ (el propio programa defina el límite máximo de ingresos de la unidad de convivencia). Así, se prevé la concesión de ayudas de hasta el $40 \%$ de la renta anual a satisfacer por el alquiler - con el límite de 2.400 euros anuales por vivienda - a quienes reúnan la condición de beneficiario, para lo que se exige la concurrencia de los siguientes requisi$\operatorname{tos}^{73}$ :

- Ser titular del contrato de arrendamiento, en calidad de arrendatario, o estar en condiciones de serlo.

- Que la vivienda arrendada o a arrendar constituya la residencia habitual y permanente del arrendatario.

- Que los ingresos de las personas que vayan a residir sean inferiores al límite máximo fijado por el Plan ${ }^{74}$.

${ }^{70}$ Proyecto de Ley por la que se modifican la Ley 35/2006, de 28 de noviembre, del Impuesto sobre la Renta de las Personas Físicas, el Texto Refundido de la Ley del Impuesto sobre la Renta de No Residentes, aprobado por el Real Decreto Legislativo 5/2004, de 5 de marzo, y otras normas tributarias. (Boletín Oficial de las Cortes Generales. Congreso de los Diputados, serie A, núm. 1071, de 6 de agosto de 2014). En el preámbulo del proyecto se explica esta reforma normativa en los siguientes términos: "se suprime la deducción por alquiler, homogeneizando el tratamiento fiscal de la vivienda habitual entre alquiler y propiedad, si bien, al igual que cuando se suprimió la deducción por inversión en vivienda, se articula un régimen transitorio para los alquileres de vivienda efectuados con anterioridad a 2015, de manera que la supresión sólo afectará a nuevos alquileres".

${ }^{71}$ PITVI, pág. III.9.

72 Art. 10 del Plan estatal de vivienda.

${ }^{73}$ Art. 11 del Plan estatal de vivienda.

${ }^{74}$ Las Comunidades Autónomas y las Ciudades de Ceuta y Melilla podrán fijar un límite inferior de ingresos de la unidad de convivencia al fijado en el Plan, en función de las circunstancias demográficas o económicas que lo aconsejen. 
- Que la renta mensual fijada en el contrato de arrendamiento sea igual o inferior a 600 euros $^{75}$.

- Que el arrendatario o u otras personas que residan en la vivienda no sean propietarias o usufructuarias de alguna vivienda en España, ni tengan parentesco en primer o segundo grado, por consanguinidad o afinidad, con el arrendador o sean partícipes o socios de la persona física que actúe como arrendador.

El segundo de los programas tiene por objeto "el fomento de la creación de un parque público de vivienda protegida para alquiler sobre suelos o edificios de titularidad pública. ${ }^{376} \mathrm{El}$ programa prevé ayudas para los posibles beneficiarios - Administraciones Públicas y entidades dependientes; Fundaciones y Asociaciones declaradas de utilidad pública: Organizaciones no gubernamentales y demás entidades sin ánimos de lucro ${ }^{77}-$ consistentes en una subvención a satisfacer al promotor de las viviendas de hasta el 250 euros $/ \mathrm{m}^{2}$ de superficie útil de vivienda. La cuantía máxima de la subvención no puede superar el $30 \%$ del coste subvencionable de la actuación, con el límite de máximo de 22.500 euros por vivienda ${ }^{78}$.

En cuanto a las condiciones de acceso a estas ayudas, las viviendas podrán proceder de promociones de nueva construcción - edificadas sobre suelo de titularidad pública - o de la rehabilitación de edificios públicos. No podrán exceder en su superficie útil de $90 \mathrm{~m}^{2}$ y pueden ser de dos tipos que se definen en razón del nivel de ingresos máximos de la unidad de convivencia permitido para acceder al alquiler: vivienda de alquiler en rotación - nivel de ingresos más bajo - y vivienda de alquiler protegido - nivel más alto -. Para que puedan calificarse como viviendas de alquiler en rotación y de alquiler protegido, es preciso que la promociones se vayan a destinar, por un plazo de al menos 50 años, en un porcentaje mínimo del $50 \%$ del número total de viviendas, al arrendamiento a inquilinos de viviendas de alquiler en rotación, y que el resto de las viviendas se califiquen - también para un plazo de al menos 50 años - como de alquiler protegido ${ }^{79}$.

En el ámbito de la comunidad andaluza, el vigente Plan concertado de vivienda prevé diversas medidas para el fomento del alquiler de vivienda. Así, el Plan dedica específicamente un capítulo a la vivienda en alquiler, que incluye cuatro programas:

${ }^{75}$ Las Comunidades Autónomas y las Ciudades de Ceuta y Melilla podrán fijar una renta mensual inferior, en función de las circunstancias demográficas o económicas que lo aconsejen.

${ }^{76}$ Art. 14 del Plan estatal de vivienda.

77 Art. 16 del Plan estatal de vivienda.

${ }^{78}$ Art. 17 del Plan estatal de vivienda.

${ }^{79}$ Arts. 14 y 15 del Plan estatal de vivienda. 
fomento de la promoción de viviendas protegidas en régimen de alquiler de renta básica a 25 años ${ }^{80}$; promoción de viviendas protegidas destinadas al alquiler a 10 años, con opción a compra, en régimen general o especial ${ }^{81}$; promoción de alojamientos protegidos de renta básica a 25 años $^{82}$, y ayudas al alquiler (ayudas a las agencias de fomento del alquiler y a los inquilinos).

Debe señalarse que la financiación cualificada que se prevé en cada uno de estos programas como incentivo para el desarrollo de las acciones contempladas en ellos, es la prevista en los correspondientes programas del Plan estatal. Ocurre que el Plan estatal vigente, que cubre el período 2013 - 2016, incorpora ya, como se ha visto, medidas distintas, no equivalentes a las del todavía vigente Plan concertado autonómico 2008-2012, lo que dificultad la operatividad de los mecanismos de financiación previstos en éste ${ }^{83}$.

El vigente plan concertado prevé, además, medidas dirigidas a colectivos sociales específicos. Concretamente, el Plan contempla un programa específico para facilitar la promoción de viviendas destinadas al alquiler con opción a compra para jóvenes ${ }^{84}$, y otros dos destinados a favorecer, respectivamente, el acceso a una vivienda protegida en régimen de alquiler a veinticinco años a familias con especiales dificultades sociales o en situación de exclusión social ${ }^{85}$; y el acceso a un alojamiento protegido en régimen de alquiler de renta básica a veinticinco años a ocupantes que se hallen en esas mismas situaciones ${ }^{86}$.

Por su parte, el borrador de Plan marco de vivienda y rehabilitación dedica también un capítulo específicamente al fomento del alquiler, que regula medidas y programas de contenido diverso.

En primer lugar, el Plan incorpora un programa de fomento del parque público de viviendas en alquiler que, en esencia, viene a ser un reenvío al contenido del programa correspondiente del Plan estatal. Por tanto, a él nos remitimos ${ }^{87}$.

\footnotetext{
80 Arts. 38 a 40 del Plan concertado.

${ }^{81}$ Arts. 41 a 43 del Plan concertado.

${ }^{82}$ Arts. 44 a 46 del Plan concertado.

83 Arts. 47 a 51 del Plan concertado.

${ }^{84}$ Arts. 56 a 58 del Plan concertado.

85 Arts. 62 a 65 del Plan concertado.

${ }^{86}$ Arts. 66 a 68 del Plan concertado.

${ }^{87}$ Arts. 36 a 38 del borrador de Plan marco.
} 
Junta a ésta, el Plan contempla las siguientes medidas referidas al parque residencial de viviendas en alquiler:

- Programa de intermediación. Este programa tiene como finalidad el mantenimiento y desarrollo de las medidas de fomento del alquiler, mediante la intermediación en el mercado del arrendamiento de viviendas y el aseguramiento de los riesgos. En concreto, las medidas que comprende este programa son: la gestión de una bolsa de viviendas deshabitadas para su cesión en arrendamiento; la concertación, a cargo de la Consejería con competencias en materia de vivienda, de pólizas de seguros de impago de renta y de defensa jurídica, así como multirriesgo de hogar, y la concesión de la asistencia técnica necesaria; el apoyo de una red de Agentes Colaboradores de la Junta de Andalucía en el desarrollo del Programa ${ }^{88}$.

- Programa de ayuda a personas inquilinas. El objeto de este programa no es otro establecer ayudas destinadas al pago de la renta del alquiler, que faciliten el acceso a la vivienda o la permanencia en la misma a familias con ingresos limitados. Así, en función del nivel de ingresos de la unidad familiar, se contemplan ayudas de hasta el $40 \%$ de la renta de alquiler ${ }^{89}$.

- Programa de alquiler de viviendas deshabitadas. Este programa tiene por objeto la reducción del número de viviendas deshabitadas, mediante la puesta en el mercado del alquiler de edificios completos o un número mínimo de viviendas en la misma localización, cuyo alquiler se gestione de manera agrupada por Administraciones Públicas, organismos y demás entidades de derecho público, fundaciones y asociaciones de utilidad pública, $\mathrm{u}$ organizaciones no gubernamentales y demás entidades privadas sin ánimo de lucro ${ }^{90}$.

Por último, también constituye una medida de fomento del alquiler la previsión contenida en el borrador de Plan marco de que las viviendas protegidas calificadas para su venta puedan ser cedidas en alquiler, bien por el promotor o persona jurídica que hubiese adquirido la vivienda, en caso de que ésta no haya podido venderse conforme al procedimiento que fuese de aplicación, bien por las personas propietarias destinatarias de las viviendas o personas promotoras para uso propio ${ }^{91}$.

En fin, éstas son las medidas de fomento del alquiler de vivienda previstas por el ordenamiento jurídico estatal y autonómico, que constituyen, junto con los instru-

\footnotetext{
88 Art. 39 del borrador de Plan marco.

89 Art. 40 del borrador de Plan marco.

90 Art. 41 del borrador de Plan marco.

91 Art. 29 del borrador de Plan marco.
} 
mentos de promoción de la rehabilitación, los pilares sobre los que han de asentarse las nuevas políticas de vivienda.

c) Otras medidas para la protección del derecho a la vivienda

Las dos líneas de actuación a que se acaba de hacer referencia no son las únicas que han de seguir los poderes públicos en esta materia. En este sentido, en la Comunidad Autónoma Andaluza, las medidas descritas en las páginas anteriores se enmarcan en un proceso ciertamente ambicioso - y no exento de controversia - de protección del derecho a la vivienda, que se inició con la Ley de 2010, ya aludida anteriormente, sobre el derecho a la vivienda en Andalucía. Este proceso experimentó nuevo desarrollo en 2013, con la aprobación por el Gobierno andaluz del DecretoLey 6/2013, de 9 de abril - convalidado por el Parlamento de la Comunidad en el mes de mayo de ese mismo año - y la posterior Ley 4/2013, de 1 de octubre, de medidas para asegurar el cumplimiento de la función social de la vivienda, que recoge el contenido de aquél (no confundir con la Ley estatal 4/2013, de junio, sobre la flexibilización del mercado del alquiler de viviendas, también referida).

La Ley andaluza 4/2013 incorpora a la Ley del Derecho a la Vivienda de 2010 nuevos mecanismos de protección de dicho Derecho, tales como la introducción de medidas para evitar la existencia de viviendas deshabitadas, entre las que se encuentran la regulación de un procedimiento para su declaración, la creación de un registro específico y actuaciones de fomento - a las que se liga el programa de alquiler de viviendas deshabitadas, antes referido ${ }^{-92}$. También ha introducido la Ley una regulación precisa de las potestades de inspección y sancionadora en materia de vivienda ${ }^{93}$.

Pero la más controvertida de las medidas previstas por la Ley 4/2013 ha sido la dirigida a defender a propietarios afectados por procesos de ejecución conducentes a la pérdida de sus viviendas.

La medida ha consistido en establecer como causa de interés, a efectos expropiatorios del uso de la vivienda por un plazo máximo de 3 años: "la cobertura de necesidad de vivienda de las personas en especiales circunstancias de emergencia social incursas en procedimientos de desahucio por ejecución hipotecaria", así como "la cobertura de necesidad de vivienda de las personas en especiales circunstancias de emergencia social que, como consecuencia de la ejecución de un aval que las mismas hayan prestado en orden a garantizar un crédito hipotecario, hayan de res-

${ }^{92}$ Nuevo Título VI de la Ley del Derecho a la Vivienda, introducido por la Ley 4/2013.

${ }^{93}$ Nuevo Título VII de la Ley del Derecho a la Vivienda, introducido por la Ley 4/2013. 
ponder con su propia vivienda habitual, por encontrarse incursas en un procedimiento de ejecución o apremio instado por una entidad financiera" y "la cobertura de necesidad de vivienda de las personas dadas de alta en la Seguridad Social como autónomas o trabajadoras por cuenta propia que se encuentren en especiales circunstancias de emergencia social y cuya vivienda habitual constituya garantía de un préstamo bancario concedido para hacer frente al desempeño de su actividad profesional y se encuentren incursas en un procedimiento de ejecución o apremio instado por la entidad financiera concedente del crédito" ${ }^{\prime 94}$.

En otros términos, la denominada medida "antidesahucio" habilita a la Administración para expropiar, por el referido plazo de 3 años, el uso de las viviendas que hayan pasado a manos de entidades financieras o sus filiales inmobiliarias, a consecuencia de un procedimiento de ejecución dirigido contra las propias viviendas o sus propietarios, siempre que en éstos concurra una situación de especial dificultad económica.

Como hemos apuntado, esta medida ha sido objeto de polémica y, en este sentido, el precepto que la introdujo - disposición adicional primera de la Ley 4/2013 ha sido recurrido junto con otros preceptos de la misma Ley ante el Tribunal Constitucional; recurso que fue admitido a trámite en enero de $2014^{95}$, lo que ha determinado, en razón de la invocación del artículo 161.2 de la Constitución, la suspensión de su vigencia ${ }^{96}$.

Por lo demás, el borrador de Plan marco contempla una diversidad de medidas en línea con la política de defensa del derecho a la vivienda - se entiende, que no tienen por objeto la promoción de la rehabilitación o el alquiler de la vivienda - . Entre ellas cabe considerar el programa andaluz en defensa de la vivienda, en virtud del cual se crea una línea de asesoramiento y protección en materia de vivienda, dirigida a personas con especiales dificultades económicas ${ }^{97}$; el fomento de las cooperativas de viviendas ${ }^{98}$; el programa de viviendas protegidas en régimen de autoconstrucción ${ }^{99}$ y el programa de permutas protegidas de vivienda ${ }^{100}$.

${ }^{94}$ Disposición Adicional Primera de la Ley 4/2013.

${ }_{95}$ Mediante Providencia de 14 de enero de 2014.

${ }^{96}$ Suspendida la vigencia de los preceptos recurridos en enero de 2014, mediante Auto de 8 de abril de 2014, el Pleno del Tribunal Constitucional ha acordado mantener la suspensión.

${ }^{97}$ Arts. 12 a 16 del borrador de Plan marco.

98 Arts. 43 a 45 del borrador de Plan marco.

${ }^{99}$ Arts. 46 a 50 del borrador de Plan marco.

100 Arts. 51 a 54 del borrador de Plan marco. 


\section{La regularización de las actuaciones urbanísticas ilegales}

La crisis del sector de la construcción ha coadyuvado a hacer más visible un fenómeno de gran relevancia: la proliferación de la edificación irregular.

Ciertamente, el ordenamiento urbanístico ofrece mecanismos para luchar contra este problema. Nos referimos a la potestad de restablecimiento de la legalidad urbanística, a través de cuyo ejercicio las Administraciones competentes - singularmente los municipios y la Comunidad Autónoma, en sustitución de éstos - pueden imponer a las propietarios la reposición de la realidad alterada, en el caso de la actuación no se ajuste a la ordenación urbanística aplicable, sin perjuicio de la imposición de las correspondientes sanciones.

Pero la cuestión no es tan sencilla. Por una parte, el ejercicio de estas potestades está sujeta, salvo en relación con determinados supuestos en los que se considera que la transgresión es especialmente grave, a un plazo de tiempo determinado. Pues bien, como ya se apuntó, durante los años de la expansión urbanizadora y residencial desmedida, los poderes públicos han mostrado una enorme pasividad respecto del fenómeno de las actuaciones urbanísticas irregulares. Ello ha supuesto que en muchos casos no sea posible accionar la potestad de restablecimiento de la legalidad contra el acto ilegal por haber transcurrido el plazo previsto para ello, circunstancia que determina su consolidación en situación de disconformidad con el planeamiento urbanístico.

Por otra parte, en ocasiones, las actuaciones irregulares vienen amparadas en una licencia otorgada por el propio municipio que es contraria a la ordenación urbanística aplicable. En tales supuestos en los que el particular ha actuado bajo la cobertura de un título administrativo, la reposición de la realidad alterada a su estado originario comporta, para el Ayuntamiento otorgante, la obligación de satisfacer al propietario afectado una indemnización que, en algunos casos, supone un gran sacrifico para la hacienda municipal.

Así las cosas, los poderes públicos han comenzado a hacer uso de un instrumento al que se ha venido a denominar regularización, concepto que, a nuestro juicio, comprende toda operación tendente a dotar de un régimen jurídico cierto a las actuaciones que se encuentran en contradicción con el ordenamiento urbanístico. Este mecanismo, por lo demás, resulta plenamente acorde con las nuevas directrices en las que deben basarse las políticas urbanas, la cuales, de conformidad con aquéllas, deben orientarse hacia el tejido urbano y residencial ya existente.

Además de lo anterior, razones vinculadas a la actual coyuntura económica puede servir de acicate para el diseño de actuaciones de regularización. 
En un momento en el que las arcas locales se encuentran vacías, los mecanismos ligados a la regularización ofrecen la posibilidad de obtener ingresos con los que paliar la drástica disminución de los que los municipios venían percibiendo a través de su participación en la gestión de los nuevos desarrollos urbanísticos y en concepto de tasas por licencias para la ejecución de nuevas actuaciones. En efecto, la gestión de la regularización facilita en muchos casos el embolso de cantidades con las que financiar actuaciones públicas de dotación o infraestructura - cuando no son ejecutadas directamente por los titulares de las propiedades sujetas a los procesos de regularización - y de recuperar las plusvalías del suelo no percibidas por la Administración en su momento. E igualmente, las licencias de legalización o títulos equivalentes que se otorguen a los propietarios una vez realizadas todas las operaciones regularizadoras pueden constituir una fuente de ingresos a través de las tasas que los municipios puedan exigir por su tramitación.

El fenómeno de la ejecución de actuaciones que se hallan en contravención con el ordenamiento urbanístico se produce tanto en el ámbito rural como en el urbano.

En lo que respecta a las actuaciones disconformes que se sitúan en el ámbito rural - en el suelo no urbanizable - la Comunidad Autonómica andaluza dispone de un marco normativo con arreglo al cuál afrontar su regularización. Éste viene constituido por el Decreto 2/2012, de 10 de enero, por el que se regula el régimen de las edificaciones y asentamientos existentes en suelo no urbanizable en la Comunidad Autónoma de Andalucía. En el tratamiento de las situaciones de ilegalidad, el Decreto establece diferentes regímenes en función de que las edificaciones tengan la consideración de aisladas o que sean constitutivas de asentamientos en suelo no urbanizable.

En cuanto a las edificaciones aisladas ejecutadas contra la ordenación urbanística, lógicamente lo que procede es ejercitar contra las mismas las potestades de restablecimiento de la legalidad, tal y como se ha señalado antes. No obstante, si ya no es posible ejercitar tales poderes por haber transcurrido los plazos legalmente previstos para ellos, esas edificaciones podrán ser declaradas, previa tramitación del oportuno procedimiento, en situación de asimilado al régimen de fuera de ordenación. Ello comporta que las edificaciones seguirán siendo ilegales, pero se permitirá su conservación mientras no se ejecute la ordenación aplicable, pudiendo autorizarse respecto de las mismas únicamente las obras exigidas para el estricto mantenimiento de las condiciones de seguridad, habitabilidad y salubridad del inmueble ${ }^{101}$.

${ }^{101}$ Arts. 3 y 8 a 12 del Decreto 2/2012. 
En el caso de los asentamientos configurados en suelo no urbanizable al margen de la legalidad urbanística, se prevé la posibilidad de su regularización mediante su incorporación a la ordenación municipal a través de dos figuras diferentes.

En primer lugar, los asentamientos que por sus características sean compatibles con el modelo territorial y urbanístico del municipio se integrarán en la ordenación mediante la clasificación, por el Plan General de Ordenación Urbanística, de los terrenos en los que se ubiquen, como suelo urbano o urbanizable. El planeamiento, igualmente, habrá de definir las obras de urbanización, de dotación y de conexión que sean precisas, cuya recepción por el Ayuntamiento posibilitará la legalización de las edificaciones existentes que sean compatibles con los parámetros de la nueva ordenación ${ }^{102}$.

En segundo lugar, los asentamientos irregularmente constituidos en suelo no urbanizable también pueden ser incorporados a la ordenación municipal, mediante su delimitación por el Plan General como ámbitos de Hábitat Rural Diseminado, dentro de aquella misma clase de suelo - no urbanizable - siempre y cuando cumplan los siguientes requisitos:

- Constituir asentamientos sin estructura urbana definida, y desvinculados de los núcleos de población existentes, siempre que constituyan áreas territoriales homogéneas.

- Estar formados mayoritariamente en su origen por edificaciones y viviendas unifamiliares vinculadas a la actividad agropecuaria y del medio rural.

- Existir una relación funcional entre las edificaciones que puedan precisar ciertas dotaciones y servicios comunes no generadores de asentamientos urbanísticos.

También en este supuesto el planeamiento habrá de definir las dotaciones y servicios que necesiten estos ámbitos ${ }^{103}$.

Esta es, de manera sintética, el remedio que ofrece el ordenamiento andaluz al problema de la consolidación de actuaciones urbanísticas contrarias al ordenamiento urbanístico. A nuestro parecer, resulta censurable, además de que sólo aborde el fenómeno en el ámbito rural, que no incorpore unas pautas sustantivas, materiales, con arreglo a los cuáles decidir qué casos pueden ser regularizados y cuáles no, lo que a su vez dificulta la configuración de soluciones estables, seguras y acordes con los principios de igualdad, proporcionalidad y desarrollo urbano sostenible.

102 Arts. 13 a 20 del Decreto 2/2012.

103 Arts. 21 a 24 del Decreto 2/2012. 
Hasta aquí el tratamiento de las actuaciones irregulares existentes en el ámbito rural. En lo que respecta a los actos urbanísticos ejecutados ilegalmente en zonas urbanas, la legislación urbanística andaluza no prevé un régimen específico, lo que no significa que tal situación no se produzca. En este sentido, es dato bien conocido que el municipio de Marbella constituye un ejemplo paradigmático de ciudad en la que existe un volumen importante de edificación ejecutada el margen de la legalidad.

A este respecto, el hecho de que no exista un régimen específico de aquellas actuaciones no ha impedido que algunos municipios andaluces hayan abordado el problema a través de sus planes, haciendo uso para ello de los mecanismos que ya proveen las normas urbanísticas autonómicas. Es el caso del Plan General de Ordenación Urbanística de Marbella (2010), que ha integrado en la nueva ordenación buena parte de las edificaciones irregulares existentes en el núcleo urbano. El Plan ha previsto, como requisito para obtener la legalización de las edificaciones, que sus propietarios satisfagan al municipio una compensación económica que se destinará a la obtención del suelo necesario y la ejecución de dotaciones y equipamientos públicos.

Así, pues, el ordenamiento urbanístico andaluz suministra herramientas para abordar el fenómeno de la edificación irregular existente en nuestro territorio. Es deseable, por la transcendencia de los problemas de inseguridad jurídica que éste genera, que los municipios hagan usos de las mismas con ocasión del ejercicio de las potestades de disciplina y de planeamiento urbanístico. Debe tenerse en cuenta, además, que el desarrollo de las operaciones regularizadoras suele conllevar la necesidad de ejecutar actuaciones de reurbanización o dotación sobre el tejido urbano existente; intervenciones que son plenamente adecuadas a las líneas directrices de las políticas urbanas que hoy se propugnan.

\section{RECAPITULACIÓN}

En el presente trabajo ha quedado puesto de manifiesto que el modelo productivo que ha seguido tradicionalmente el ramo de la construcción, basado en el crecimiento urbano desmesurado y apoyado de un modo excesivo en el incremento del parque residencial, se encuentra agotado. Así las cosas, es necesaria una reconversión del sector que resuelva los problemas estructurales de que adolece y evite que el futuro se produzcan los impactos que en el plano económico, social y ambiental ha generado el urbanismo de expansión.

Dicha reconversión ha de realizarse sobre la base de unas pautas que derivan del principio de desarrollo urbano sostenible, configurado a partir de una diversidad de documentos de origen internacional y comunitario, y que ya ha encontrado acogida en nuestra legislación sobre suelo. Todos estos documentos han terminado por per- 
filar un modelo de ciudad sostenible, el de ciudad compacta, que se caracteriza por su alta densidad, el policentrismo, y por priorizar la rehabilitación y renovación de la ciudad existente frente a nuevos crecimientos.

En ese concepto de ciudad se enmarca la estrategia del Ministerio de Fomento para la recuperación y dinamización del sector de la construcción y la vivienda, que, tal y como se ha expresado, propone como aspectos clave de las nuevas políticas urbanas la regeneración y renovación del tejido urbano, la rehabilitación edificatoria y el fomento del alquiler de viviendas. Estas directrices encuentran materialización en las recientes Leyes estatales de rehabilitación, regeneración y renovación urbanas y de medidas de flexibilización y fomento del mercado de alquiler de viviendas. Asimismo, el nuevo plan estatal de vivienda incorpora programas de fomento totalmente en línea con las referidas directrices. En el ámbito de la Comunidad Autónoma andaluza, el nuevo plan de vivienda - aún en proceso de aprobación - también es acorde con aquellas orientaciones. Además, en esta Comunidad se ha apostado fuertemente por la protección del Derecho a la Vivienda, a través de la Ley reguladora de tal Derecho y de la de medidas para asegurar el cumplimiento de la función social de la propiedad.

Por último, las nuevas políticas sobre suelo han de abordar el fenómeno de la consolidación de edificaciones y parcelaciones contrarias al ordenamiento urbanístico, mediante la previsión y ejecución de medidas dirigidas a clarificar el régimen aplicable a las mismas. A tal objeto responde el Decreto aprobado por la Junta de Andalucía sobre el régimen de las edificaciones y asentamientos existentes en suelo no urbanizable, una disposición que afronta el problema pero exclusivamente en el ámbito rural.

\section{REFERENCIAS}

- FOTOCASA - IESE (UNIVERSIDAD DE NAVARA). Informe de la vivienda en alquiler en España. Tercer trimestre de 2014. http://prensa.fotocasa.es

- INSTITUTO NACIONAL DE ESTADÍSTICA. Cuentas económicas. Contabilidad nacional de España. PIB a precios de mercado. Serie 2000-2012. http://www.ine.es/

- MINISTERIO DE FOMENTO. Información estadística sobre construcción (licitación oficial en construcción, construcción de edificios y obras en edificación) y vivienda y actuaciones urbanas (vivienda protegida, vivienda libre, transacciones inmobiliarias y precio de la vivienda) http://www.fomento.gob.es/. 